\title{
Effect of Essential Oils and GRAS Compounds on Postharvest Disease Control in Mango (Mangifera indica L.cv Tom EJC)
}

\author{
K. I. M. Kalupahana ${ }^{1}$, M. Kuruppu ${ }^{2}$ and P. K. Dissanayake ${ }^{1^{*}}$ \\ Date Received: $10^{\text {th }}$ November 2019 / Date Accepted: 22 $2^{\text {nd }}$ February 2020
}

\begin{abstract}
Purpose : Mango (Mangifera indica L. cv. Tom EJC) has a high economic value due to its unique qualities. Postharvest diseases such as anthracnose cause considerable loss of fruits in the market. Applications of synthetic fungicides are the common practice for controlling postharvest diseases, which could lead to hazardous effects on health. Therefore, search for alternative measures for the control of anthracnose are in demand.

Research Method:Different fungal species have been described as causative agents of above disease. To determine the causative agent, fungal isolations were done from symptomatic fruits and identified by morphological and molecular techniques. Sodium bicarbonate, and sodium metabisulphite were used as GRAS (Generally Recognized as Safe) compounds and clove, cinnamon and citronella oils were used as essential oils during in-vitro studies to evaluate their potential to control the pathogen. The mycelial inhibitory capacity of five concentrations (1 $\mu$ Lplate-1-5 $\mu$ Lplate-1) of each essential oil was evaluated in-vitro disc volatilization method. Compounds with minimum inhibitory concentrations were selected for in-vivo studies. Essential oil treatments for mango comprised of fumigation and application of GRAS compounds by dipping 15 and 30 minute time intervals. Physiochemical properties ( $\mathrm{pH}$, titrable acidity and total soluble solid content) of treated and non-treated mango fruits were evaluated.
\end{abstract}

Findings : The identified causative agent of anthracnose was Colletotrichum siamense. Sodium bicarbonate (80000ppm), sodium metabisulphite (1500ppm) showed $100 \%$ inhibition of radial mycelia growth against the pathogen through in-vitro poison food method.100\% inhibition of radial mycelia growth was reported with clove and cinnamon oil at all the concentrations tested (1-5 LLplate-1). The citronella oil showed the lowest inhibitory activity. 15 minute and 30 minute dipping in sodium bicarbonate and fumigation with clove oil and cinnamon oil treatments effectively controlled anthracnose disease in mango, in comparison to the recommended fungicide Chlorothalonil $(3 \mathrm{~mL} / \mathrm{L})$. Physiochemical properties of mango were not altered by any of the treatments in comparison to no-treated fruits.

Originality /Value : These results suggest that Sodium bicarbonate, Clove oil and Cinnamon oil could be used as alternatives to control the anthracnose disease in mango.

Keywords: Anthracnose, Colletotrichum siamense, Essential oils, GRAS compounds

\section{INTRODUCTION}

Mango (Mangifera indica L.), which belongs to family Anacardiaceae, is one of the most popular fruit crops in Sri Lanka and other tropical and subtropical countries. Mango has many industrial uses, and a high food value. Fruit is a rich source of total solids, proteins, starch and vitamins (Salunkhe and Desai, 1984). It is a widely cultivated tree fruit in Sri Lanka with a present extent of about 28772 ha and the total of $151733 \mathrm{mt}$ (Anonymous). The novel variety of Tom EJC has unique properties, which resulted in being popular among other recommended mango varieties in Sri Lanka. It

\footnotetext{
$I^{*}$ Department of Export Agriculture, Faculty of Agricultural Sciences, Sabaragamuwa University of Sri Lanka, Belihuloya, Sri Lanka.

kapila@agri.sab.ac.lk

2 Fruit Research and Development Institute, Kananwila, Horana, Sri Lanka
}

(1) ORCID http://orcid.org/0000-0003-2488-3373 
is the largest, juiciest mango variety. Tom EJC has an attractive golden orange clear skin with smooth flesh, excellent flavor, aroma and low fiber content. It has high demand in the local and export markets. Tom EJC mango takes time from producer to consumer due to slow ripening ability (Wijesinghe et al., 2011). Its perishable nature limits the shelf life due to postharvest diseases. Postharvest diseases of mango reduce the quality of fruit resulting in severe marketable losses (Narayanasamy, 2006). In a study conducted at Batticaloa district, Sri Lanka, it has been recorded that postharvest losses are about $34.67 \%$ of total produced mango (Mahendranathan, 2018).

Anthracnose is the most serious disease in humid growing areas (Fitzell and Peak, 1984; Arauz, 2000). It is a common destructive and wide spread disease in Asian and other mango growing areas of the world with pre- and postharvest losses. Symptoms of the disease on the fruits appear at initial stage as small, dark brown, circular spots that enlarge and coalesce to form bigger and sunken spots during ripening (Arauz, 2000). Colletotrichum species are the causal agents of the anthracnose disease, which also affect a number of crops including temperate and tropical fruits and legumes (Fitzell and Peak, 1984). Therefore, it is needed to develop new and acceptable postharvest disinfection methods to minimize the disease. When developing such methods apart from the ability to control the disease, commodity quality, practicability, implementation costs, environment friendly and consumer friendly technologies have to be considered.

The use of synthetic fungicides on plant materials, especially on food crops has become questionable. The main reason is the toxicity to humans. The use of these chemicals may lead to the presence of residues in food, which represent a toxicological hazard to human health. Synthetic pesticides are a source of environmental contamination and have a long degradation period (Tripathi \& Dubey, 2004). This is important in the case of fruit, since nowadays there is a rising consumer awareness of the need to follow a healthier diet, in which the role of fruit is essential. Fungicides have been a major cause for development of resistant fungal strains. Therefore, it is highly important to introduce alternatives for chemical fungicides (Dissanayake et al., 2015).

The Generally Recognized as Safe (GRAS) compounds, are considered as the risk reducing chemicals in postharvest technology (Lewthwaite et al., 1997) and different essential oils are being used as alternatives to control postharvest diseases. When compared to other GRAS compounds sodium bicarbonate and sodium metabisulphite have several advantages. These are ease of handling and use, low cost and have ample availability. Essential oils of different plant origins have previously reported to contain fungicidal properties in-vitro as well as in-vivo studies (Duamkhanmanee, 2008). They are safe for environment and at present, many of them are used as flavoring agents in food industry. The general antifungal activity of essential oils is well documented (Meepagala et $a l ., 2002$ ) and several studies have recorded the effects of essential oils on postharvest pathogens. Essential oils are bioactive in vapor phase, biodegradable with short degradation periods that make them attractive as possible fumigants for stored product protection (Sivakumar and Bautista-Banos, 2014). The overall objective of this project was to control anthracnose disease in mango Tom EJC using essential oils and GRAS compounds at postharvest stage instead of chemical fungicides.

\section{MATERIALS AND METHODS}

\section{Location}

The experiment was carried out at Fruit Research and Development Institute, Department of Agriculture, and in the laboratory of the Division of Plant Pathology, Kananwila, Horana, in 2019.

\section{Isolation of fungi}

Symptomatic fruits of Tom EJC mango were collected from the local market and were transferred to the laboratory for isolation. Diseased mango tissues $\left(4 \mathrm{~mm}^{2}\right)$ were cut from margins of symptomatic areas under aseptic conditions. The tissues were washed using two drops of teepol and running tap water for 
20 minutes. Tissues were surface sterilized by soaking the sections in freshly prepared $\mathrm{NaOCl}$ $(0.1 \% \mathrm{w} / \mathrm{v})$ for 3 minutes (Anthony et al., 2004). After three serial washings in sterile distilled water, mango tissues were placed (4 pieces per plate) on sterile Potato Dextrose Agar (PDA), and incubated at room temperature $\left(28 \pm 2^{\circ} \mathrm{C}\right)$ for seven days.

When fungal growth was visible on the tissue, each fungus was sub cultured on PDA and re- incubated to obtain pure cultures for identification purposes. The fungal pathogens were identified by studying their morphological characters under Phase Contrast Microscopy (×400 magnification) (Olympus CX41 model, Tokyo, Japan) using slide cultures. The identity of the test pathogens were confirmed by molecular tools at Gene tech Institute, Sri Lanka (Tafinta et al., 2013).

\section{Molecular identification procedure}

Three isolates (isolate 01 , isolate 02 and isolate 03) were chosen for molecular studies. Total genomic DNA which were isolated from the pure fungal cultures were amplified and purified using PCR technique by Plant Virus Index Centre (PVIC), Homagama, and then DNA sequencing by Gene tech Institute, Sri Lanka.

Using Basic Local Alignment Search Tool (BLAST) the sequences were compared with the sequences in the National Center for Biotechnology Information (NCBI) database and particular fungal species were identified at the Division of pathology, Fruit Research and Development Institute, Horana. Appropriate sequences will be deposited in the Gene Bank.

\section{Assessment of the pathogenicity for anthracnose disease}

Healthy, matured and uninjured fruits of Tom EJC mango were washed with running tap water to remove all dirt, debris and then surface sterilized by using $70 \%$ alcohol for 30 seconds. Subsequently, fruits were washed with sterile distilled water and allowed to drip dry for 30 minutes on a laboratory bench. Fruits were wounded by puncturing, using a sterile needle. Each wound site was inoculated with a $7 \mathrm{~mm}$ diameter mycelial disc from 7day old culture of respective fungal isolates and incubated in humid chamber.

After the appearance of disease symptoms in the inoculated fruits, the pathogens were reisolated on PDA from diseased fruits. Under light microscope, morphological criteria of the re-isolated fungi were compared and matched with the originally inoculated fungi.

\section{Essential oils and Generally Recognized as Safe (GRAS) Compounds}

Cinnamomum zeylanicum (Cinnamon) oil, Syzygium aromaticum (Clove) oil, Cymbopogon nardus (Citronella) oil, sodium bicarbonate, and sodium metabisulphite were purchased from Glorechem Enterprise, Colombo.

\section{In-vitro disc volatilization method}

The essential oils including cinnamon, clove and citronella oils were tested for antifungal activity in-vitro by adopting a disc volatilization method (Dafarera et al., 2000). The experiments were conducted in Petri plates (70 $\mathrm{mm}$ in diameter) of PDA and each plate was inoculated with 7 $\mathrm{mm}$ fungal disc cut from the periphery of a 7 day old culture of a respective test pathogen (Bill et al., 2015).

A sterilized filter paper with a diameter of 70 $\mathrm{mm}$ (Whatman No: 1) disc was placed in the lid. An aliquot of selected essential oil $(1-5 \mu \mathrm{L}$ plate-1) was added onto the filter paper discs using a micropipette. Sterilized distilled water without oil served as the control. Five replicates were used per treatment.

Petri plates were tightly sealed with para-film immediately after adding essential oil and incubated at room temperature $\left(28 \pm 2^{\circ} \mathrm{C}\right)$ for 7 days. The plates were kept in an inverted position throughout the incubation period. Diameter of radial mycelial growth was measured in two perpendicular directions using a centimeter ruler on a daily basis. The antifungal efficacy was expressed as the percentage inhibition of radial mycelial growth (\% IRMG) using the formula given by Abdollahi et al., (2011). 


$$
\% I R M G=\frac{(d c-d t) \times 100}{d c}
$$

Where, $\mathrm{dc}=$ radial mycelial growth measurements in control Petri plates

$\mathrm{dt}=$ radial mycelial growth measurements in treatment Petri plates

\section{In-vitro Poisoned food method}

Sodium bicarbonate and sodium metabisulphite were tested for antifungal activity in-vitro by using Poisoned food method (Ali-Shtayeh et al., 1999). Conical flasks (500 ml) containing $400 \mathrm{ml}$ of PDA was autoclaved for 20 minutes at $1.03 \mathrm{Kgcm}^{-1}$ and $121^{\circ} \mathrm{C}$. Sodium bicarbonate and sodium metabisulphite, were incorporated into sterilized PDA that was cooled to $45{ }^{\circ} \mathrm{C}$ at desired final concentrations and mixed well. Then, the medium was poured into petri plates (70mm) under aseptic conditions.

Plates were inoculated with $7 \mathrm{~mm}$ fungal discs cut from the periphery of a 7 day old culture of a respective test pathogen. Plates without of compounds were used as the control. Five replicates were used per treatment. Plates were tightly sealed with parafilm and incubated for 7 days at room temperature $\left(28 \pm 2^{\circ} \mathrm{C}\right)$.

Radial mycelial growth was measured by measuring the colony diameter in two perpendicular directions using a ruler on a daily basis. The antifungal efficacy was expressed as the percentage inhibition of radial mycelial growth (\% IRMG) using the formula given by Abdollahi et al., (2010).

\section{Experimental Design}

The experiment was laid out in a completely Randomized Design (CRD) with five replicates. The data obtained were analyzed using Analysis of Variance (ANOVA). Duncan's Multiple Range Test (DMRT) was used to compare differences among the treatments in-vitro.

Effect of test essential oils and Generally Recognized as Safe (GRAS) compounds on anthracnose disease

\section{Preparation of mango}

Mature, unblemished and healthy Tom EJC mango fruits were collected from the market. Fruits were washed with running tap water to remove dirt and debris. Surface of fruits were sterilized by dipping the fruit in teepol for 20 minutes and subsequently in distilled water, and air-dried at room temperature (Bill et al., 2015).

\section{Artificial inoculation and disease progress}

The mango fruits were exposed to (i) chlorothalonil $3 \mathrm{~mL} / \mathrm{L}$ (negative control), (ii) clove oil fumigation iii) cinnamon oil fumigation iv) sodium bicarbonate v) sodium metabisulphite vi) sterile distilled water dip (positive control).

\section{Clove oil and cinnamon oil fumigation}

The clove oil and cinnamon oil concentrations were selected $\left(1 \mu \mathrm{L}\right.$ plate $\left.{ }^{-1}\right)$ based on the minimum effective concentrations from invitro test by disc volatilization method. The clove oil $268 \mu 1$ was calculated proportionally to the volume of the container. Oil sample was introduced into a $12.5 \mathrm{~L}$ translucent plastic container $(90 \% \mathrm{RH})$ by placing the clove oil and cinnamon oil in a petri plate $(70 \mathrm{~mm}$ in diameter) lid inside the container of the fruits. Two mango fruits were carefully placed in each container $\left(31 \times 25 \times 16 \mathrm{~cm}^{3}\right.$, translucent plastic) so as to avoid contact between the fruit and oil. The container was immediately sealed with a slip on lid to start the fumigation process. The fruits were exposed to clove oil and cinnamon oil vapor for 24 hours at room temperature and thereafter placed on sterile paper towel on bench tops for inoculation (Bill et al., 2015).

\section{Sodium bicarbonate, Sodium metabisulphite and chlorothalonil treatments}

The sodium bicarbonate (80000ppm), sodium metabisulphite (1500ppm) and commercial chlorothalonil $(3 \mathrm{~mL} / \mathrm{L})$ concentrations were selected from the in-vitro by Poison food method based on the minimal effective concentrations.

Each test compound was added to the 5L of distilled water separately. Fruits were dipped for 15 minute and 30 minute time intervals in each effective compound. Fruits were taken out and excess solutions were allowed to drain out. All treated and control samples were placed 
separately in plastic trays. Fruits were uniformly wounded to a depth $1.5 \mathrm{~mm}$ by punching them with a sterilized needle. Each wound site of fruit was inoculated with a mycelial disc $(7 \mathrm{~mm})$ of pathogen from a seven day old culture separately. Each set of fruits consisting of two replicates were placed in plastic containers disinfected with ethanol $(70 \%)$. A piece of sterile cotton wool soaked in sterile distilled water was placed on each container to provide moisture for fungal growth.

Mean lesion diameter was taken on two perpendicular axes seven days after inoculation to identify development of disease on fruits.

\section{Experimental Design}

The experiment was laid out as a completely Randomized Design (CRD) with seven treatments and two replicates. The data obtained were analyzed using Analysis of Variance (ANOVA) procedure. Duncan's Multiple Range Test (DMRT) was used to compare differences among the treatments in-vivo.

\section{Assessment of physicochemical properties}

To identify difference among treatments physiochemical analysis of fruit was carried out.

\section{Total soluble solids (Brix value) content}

Pulp (25g) obtained from the mesocarp of the each fruit was stirred respectively with distilled water $(25 \mathrm{ml})$. The homogenate was filtered through a muslin cloth. Few drops of the filtrate were used to measure TSS using a Pocket Refractometer (PAL - $\alpha$, Cat.No.3840, ATAGO Co, Ltd, Japan).
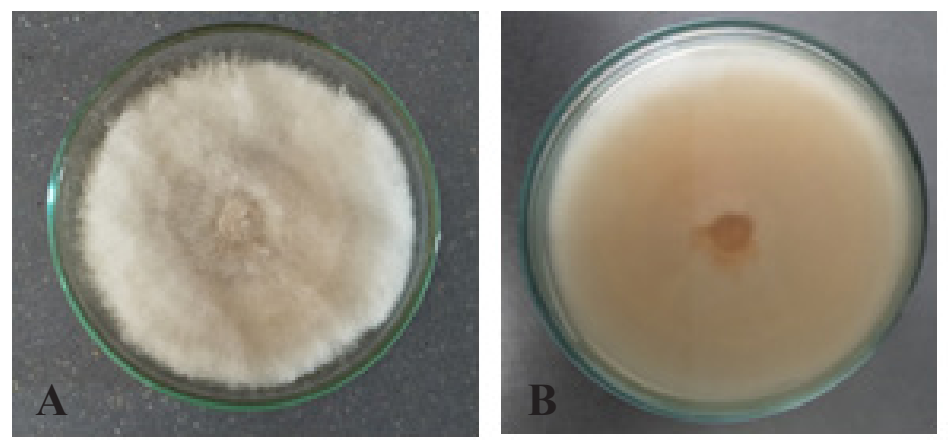

C

\section{pH value}

$\mathrm{pH}$ of the 1:1 homogenous samples were measured using a Bench top $\mathrm{pH}$ meter $(\mathrm{pH}$ 7110, WTW, Germany).

\section{Titrable acidity}

Flesh of the mangoes was squeezed well and $6 \mathrm{ml}$ of juice obtained from each mango fruit was diluted with $50 \mathrm{ml}$ of distilled water. The aliquot was titrated with standardized $0.1 \mathrm{~N}$ sodium hydroxide $(\mathrm{NaOH})$ in the presence of phenolpthaline as an indicator. The end point was taken as the sudden appearance in pink color. The acidity percentage was calculated using the following equation.

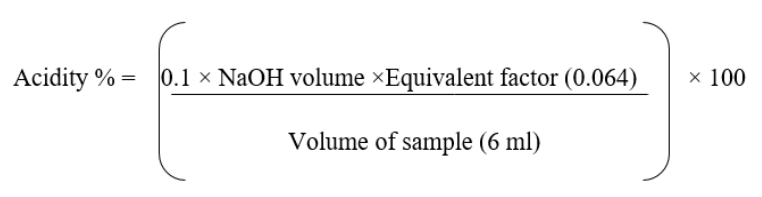

\section{RESULTS AND DISCUSSION}

\section{Identification of Possible Pathogens on morphological observations}

\section{Isolate 1}

Isolate 1 initially produced white colony which later turned grayish (Figure 01A) and the reverse was pale yellowish to orange colour on PDA media (Figure 01B). Aerial mycelia were grayish white and cottony appearance. Fungus reached $7 \mathrm{~cm}$ diameter within 7 days. Setae were absent. The conidia were cylindrical with smooth wall, obtuse to slightly rounded ends (Figure 01C). Sclerotia were present. Appressorial shapes produced by the fungus were ovate in shape.

\section{Figure 01: Seven day old pure culture of Isolate 1 on PDA}




\section{Isolate 2}

Fungus grew rapidly on PDA reaching $7 \mathrm{~cm}$ diameter in 7 days at $28^{\circ} \mathrm{C}$. Mycelium was cottony white, later turning greyish brown in colour and concentric rings were visible on the surface of mature culture (Figure 02A). The reverse of the colony was also grey-brown. (Figure 02B). Mycelium was branched, septate and hyaline. Conidia extruded from ostioles in white mass. Conidia were hyaline, aseptate and fusoid to ellipsoid 5.3-6.10 $\times 1.6-2.30 \mu \mathrm{m}$. Sporulation was observed under laboratory conditions, during the last period of study.

\section{Isolate 3}

Colonies on PDA reached $38-45 \mathrm{~mm}$ average growth after three days at $28^{\circ} \mathrm{C}$. Colony appeared white initially and turned pale salmon and cottony on maturity (Figure 03A). The reverse of the colony was violet (Figure 03B). Two types of spores were produced on conidiophores known as macro conidia and micro conidia. Shape of micro conidia were fusiform and allantoid and aseptate and straight or curved. Macro conidia were hyaline, two to several celled, fusiform to sickle shaped.

\section{Identification of pathogenson molecular basis}

Three isolates (Isolates 1, 2 and 3) were analyzed using ITS sequences and were subjected to BLAST search. DNA sequences of the isolate 1 based on molecular results (Table 01) were $98.45 \%$ similar to the $C$. siamense. Isolate 2 were $99.22 \%$ similar to the Diaporthe perseae and Isolate 3 were $100 \%$ similar to the Fusarium lacertarum (Table 01).

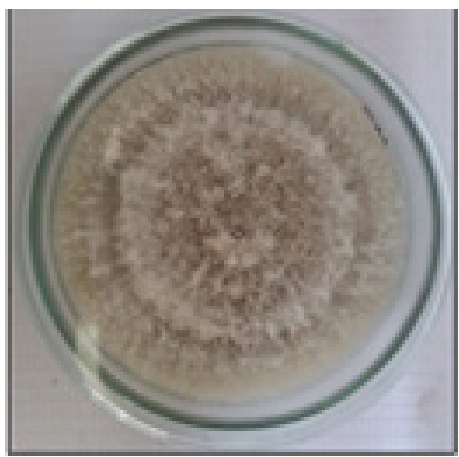

A

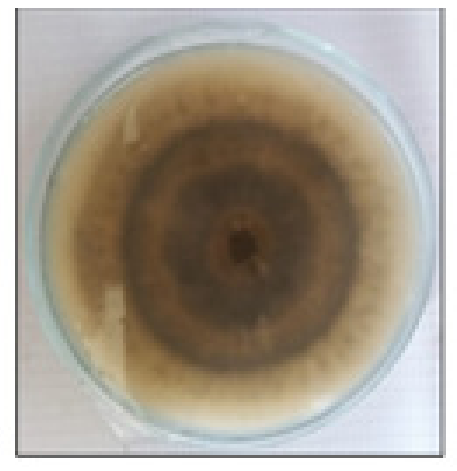

B

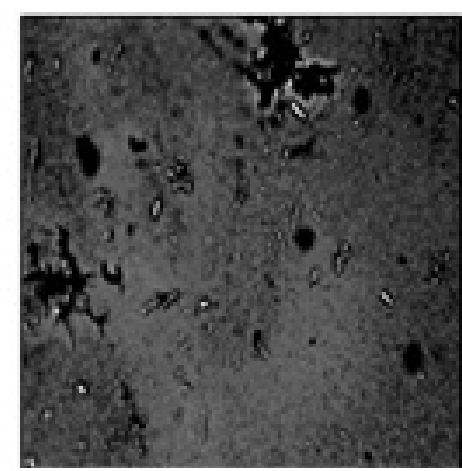

C

Figure 02: $\quad$ Seven day old pure culture of Isolate 2 on PDA

A- White greyish brown upper surface; B- Grey brown lower surface; C-Conidia of 42 day old pure culture of Isolate 2observed under Phase Contrast Microscopy at $\times 400$ magnification

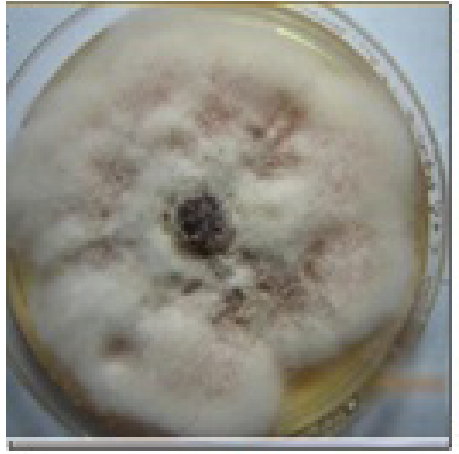

A

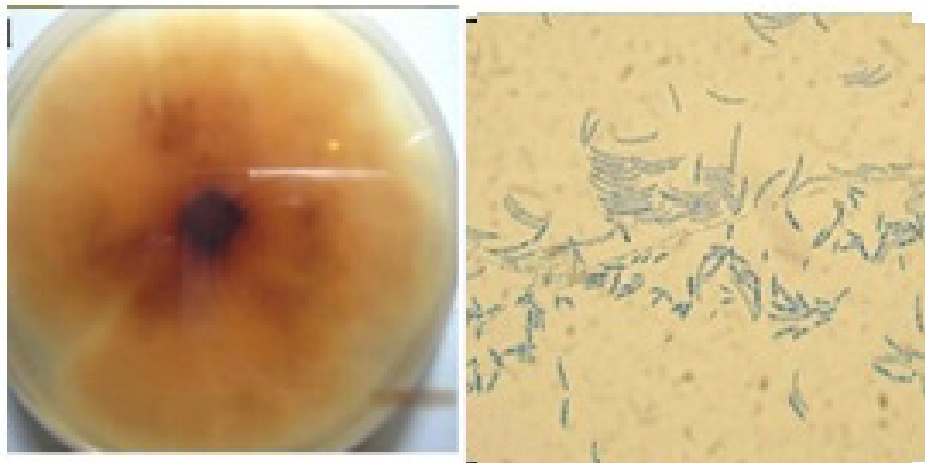

B
C

Figure 03: $\quad$ Ten day old pure culture of Isolate 3 on PDA

A-White upper surface; B-Brown orange lower surface; C-Conidia of pure culture of Isolate 3 observed under Phase Contrast Microscopyat $\times 400$ magnification 
Table 01: Homology results of the isolated pathogens

\begin{tabular}{|c|c|c|c|c|}
\hline Edited Sequence & $\begin{array}{c}\text { Query } \\
\text { coverage }\end{array}$ & $\begin{array}{c}\mathrm{E} \\
\text { Value }\end{array}$ & $\%$ Identity & Homology \\
\hline $\begin{array}{l}\text { TGACATACCTATACGTTGCCTCGGCGGATCAGCCCGCG- } \\
\text { CCCCGTAAAACGGGACGGCCCGCCCGAGGACCCCTA- } \\
\text { AACTCTGTTTTTAGTGGAACTTCTGAGTAAAACAAA- } \\
\text { CAAATAAATCAAAACTTTCAACAACGGATCTCTTG- } \\
\text { GTTCTGGCATCGATGAAGAACGCAGCAAAATGCGA- } \\
\text { TAAGTAATGTGAATTGCAGAATTCAGTGAATCATC- } \\
\text { GAATCTTTGAACGCACATTGCGCCCGCCAGTATTCT- } \\
\text { GGCGGGCATGCCTGTTCGAGCGTCATTCAACCC- } \\
\text { CAAGCTCAGCTGGGTGTGGGACTCGCGGTAACCCG- } \\
\text { CGTTCCCCAAATCGATTGGCGGTCACGTCGAGCTTC- } \\
\text { CATAGCGTAGTAATCATACACCTCGTTACTGGTAATC- } \\
\text { GTCGCGGCCACGCCGTAAAACCCCAACTTCTGAAT- } \\
\text { GTTGACCTCGGATCAGGTAGGAATACCCGCTGAAC }\end{array}$ & $100 \%$ & 0.0 & $100.00 \%$ & $\begin{array}{l}\text { Fusarium lacertarum } \\
\text { isolate G4 internal } \\
\text { transcribed spacer } 1\end{array}$ \\
\hline $\begin{array}{l}\text { AAACCCTTTGTGAACTTATACCTTTTGTTGCCTC- } \\
\text { GGCGCTGCTGGTCTTCACAGGCCCTTGCTTCA- } \\
\text { CAGCAAAGAGACGGCACGCCGGCGGCCAAGTTA- } \\
\text { ACTCTTGTTTTTACACTGAAACTCTGAGAAAAAACA- } \\
\text { CAAATGAATCAAAACTTTCAACAACGGATCTCTTG- } \\
\text { GTTCTGGCATCGATGA } \\
\text { AGAACGCAGCGAAATGCGATAAGTAATGTGAATTG- } \\
\text { CAGAATTCAGTGAATCATCGAATCTTTGAACGCA- } \\
\text { CATTGCGCCCTCTGGTATTCCGGAGGGCATGCCTGTTC- } \\
\text { GAGCGTCATTTCAACCCTCAAGCATTGTTGGGTGTTGG- } \\
\text { GGCACTGCTTCTAACGAAGCAGGCCCTGAAATCTAGT- } \\
\text { GGCGAGCTCGCCAGGACCCCGAGCGCAGTAGTTAAAC- } \\
\text { CCTCGCTCTGGAAGGCCTGGCGGTGCCCTGCCGTTA- } \\
\text { AACCCCCAACTTCTGAAAATTTGACCTCGGATCAGG- } \\
\text { TAGGAATACCCGCTGAACTTAAGCATATCAAAAC }\end{array}$ & $100 \%$ & 0.0 & $99.22 \%$ & $\begin{array}{l}\text { Diaporthe perseae } \\
\text { isolate ASHM300 } \\
\text { small subunit } \\
\text { ribosomal RNA gene }\end{array}$ \\
\hline $\begin{array}{l}\text { TTTTGTGACATTACCTTATAACTTGTTGCTTTCCGGC- } \\
\text { GGGTAGGGTCCTCCCGTGACCCTCCGGCCTCCCG- } \\
\text { CCCCCGGGCGGGTCGGCGCCCGCCGGAGGATAAC- } \\
\text { CAAACTCTGATTTAACGACGTTTCTTCTGAGTGGTA- } \\
\text { CAAGCAAATAATCAAAAACTTTAACAACACGGATCTCTTG- } \\
\text { GTTCTGGCATCGATGAAGAACGCAGCGAAATGCGA- } \\
\text { TAAGTAATGTGAATTGCAGAATTCAGTGAATCATC- } \\
\text { GAATCTTTGAACGCACATTGCGCCCGCCAGCATTCT- } \\
\text { GGCGGGCATGCCTGTTCGAGCGTCATTTCAACCCT- } \\
\text { CAAGCTCTGCTTGGTGTTGGGGCCCTACAGCTGATG- } \\
\text { TAGGCCCTCAAAGGTAGTGGCGGACCCTCCCGGAG- } \\
\text { CCTCCTTTGCGTAGTAACTTTACGTCTCGCACTGG- } \\
\text { GATCCGGAGGGACTCTTGCCGTAAAACCCCCAATTTC- } \\
\text { CAAAGGTTGACCTCGGATCAGGTAGGAATTACCCG- } \\
\text { GCTGAACTTAAGCATTCTAA }\end{array}$ & $98 \%$ & 0.0 & $98.45 \%$ & $\begin{array}{l}\text { Colletotrichum } \\
\text { siamense strain } \\
\text { GDBL-6 internal } \\
\text { transcribed spacer 1, }\end{array}$ \\
\hline
\end{tabular}

\section{Assessment of the pathogenicity}

Pathogenicity of $C$. siamense was confirmed by the visualized symptoms of anthracnose disease such as black sunken patches of mango after wound inoculation three days after incubation at room temperature. After the symptoms, pathogens were re-isolated. Disease was identified as anthracnose according to the morphological and molecular results.

\section{Effect of GRAS compounds and Essential oilsagainst $C$. siamense}

\section{Sodium bicarbonate}

Mean radial mycelial growth of $C$. siamense pathogen was inhibited completely $(100 \%)$ by both 80000 and $90000 \mathrm{ppm}$ concentrations of Sodium bicarbonate (Figures 04 and 6). On that basis the concentration 80000ppm was selected for in-vivo studies as minimum effective concentration of sodium bicarbonate. Radial mycelial growth was inhibited by $91.46 \%$, $87.92 \%$ and $86.25 \%$ Sodium bicarbonate concentrations of 70000,60000 and $50000 \mathrm{ppm}$, respectively.

These are contradictory to the results of Sivakumar et al., (1999) who had obtained $10,000 \mathrm{ppm}$ concentration as minimum level of sodium bicarbonate against C. gloesporioides causing anthracnose of Rambutan under invitro conditions. This could be mainly due to species difference and hence this implies that 
different species need different specific test to find effective minimum concentrations.

\section{Sodium metabisulphite}

Inhibition of radial mycelial growth increased with increasing concentrations of sodium metabisulphite (Figures 05 and 06). Inhibition of radial mycelial growth reached $100 \%$ at $1500 \mathrm{ppm}$ concentration of sodium metabisulphite, which was significantly different from other concentrations. On this basis 1500 ppm concentration was selected for in-vivo studies as minimum effective concentration of sodium metabisulphite. Radial mycelial growth inhibitions of $81.87 \%, 65.42 \%$ and $55.62 \%$ were achieved by sodium metabisulphite concentrations of 1250, 1000 and 750ppm, respectively. There was no significant difference between 1000ppm and 750ppm.

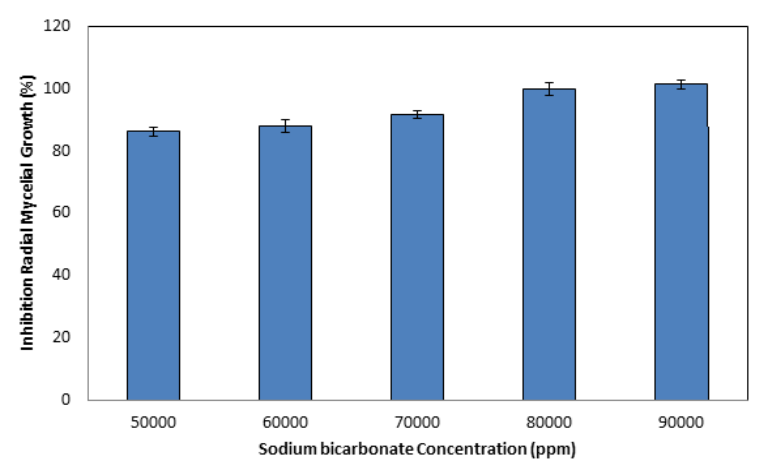

Figure 04: Percentage inhibition of radial mycelial growth of $\mathrm{C}$. siamense with different Sodium bicarbonate concentrations.
These are contradictory to the results of Sivakumar et al., (1999) who had previously reported that $250 \mathrm{ppm}$ as the minimum effective concentration of sodium metabisulphite to achieve $100 \%$ growth inhibition of $C$. gloeosporioides causing anthracnose of Rambutan.

When considering the fungicidal effects of the GRAS compounds sodium bicarbonate and sodium metabisulphite can be recognized as effective against the pathogens in-vitro (Mills et al., 2004, Sivakumar et al., 2002). Sodium bicarbonate has been broadly used in the food industry (Olivier et al., 1998) and Sodium metabisulphite is commonly used as a preservative in food industry throughout the world (Smith, 1980; Stattery et al., 1990).

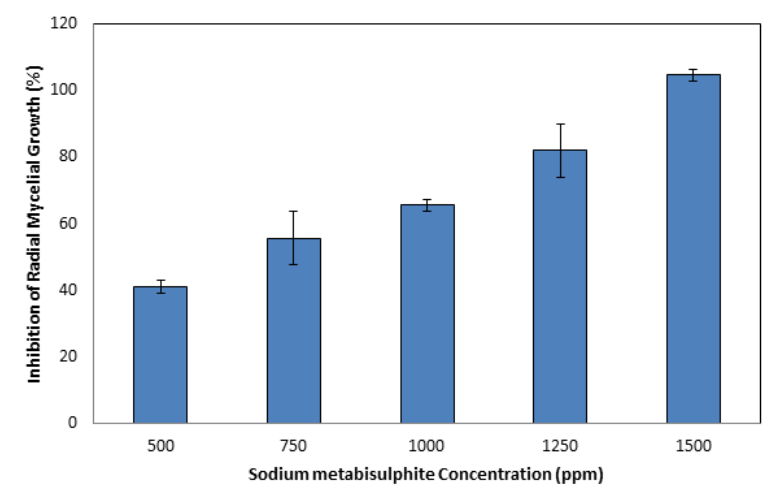

Figure 05: Percentage inhibition of radial mycelial growth of $\mathrm{C}$. siamensein the Sodium metabisulphite
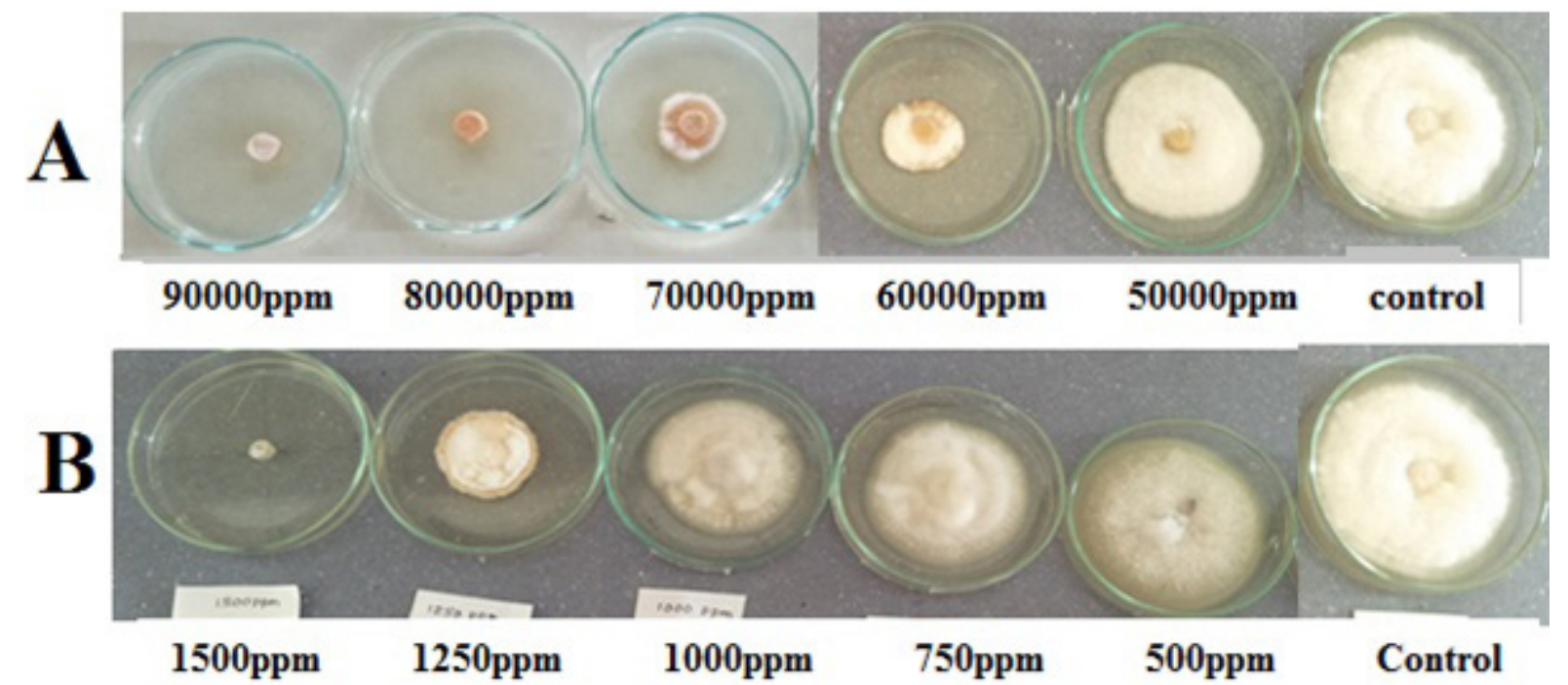

Figure 06: Mycelial growth of $\mathrm{C}$. siamense exposed to different concentrations of sodium bicarbonate (A) and sodium metabisulphite (B) at day seven. 


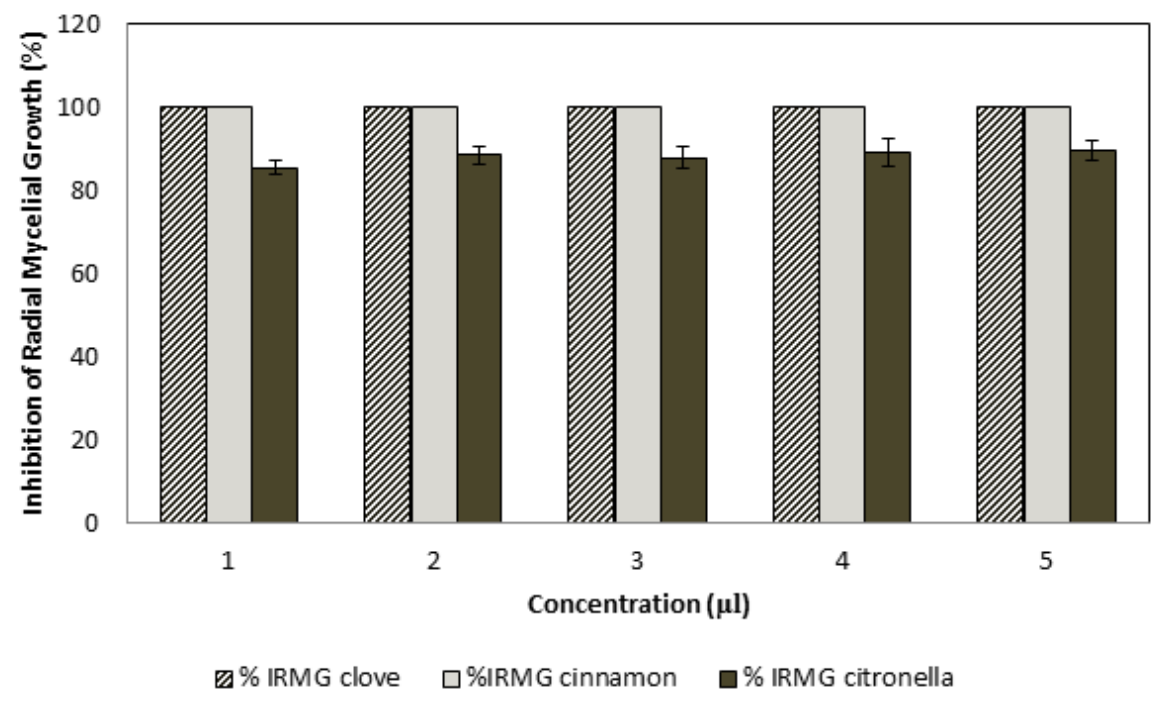

Figure 07: Percentage inhibition of radial mycelial growth of $\mathrm{C}$. siamense under different concentrations of Clove, Cinnamon and Citronella oils

\section{Essential oils}

All the test concentrations $(1,2,3,4$, and $5 \mu$ Lplate $\left.^{-1}\right)$ of clove oil and cinnamon oil showed $100 \%$ radial mycelial growth inhibition .There was no significant difference between these treatment concentrations. Clove oil $\left(1 \mu\right.$ Lplate $\left.^{-1}\right)$ and cinnamon oil $\left(1 \mu\right.$ Lplate $\left.^{-1}\right)$ were identified as the minimum effective concentrations. Citronella oil showed the lowest inhibitory activity against test fungus. Moreover, within the tested range of concentrations citronella oil did not show $100 \%$ of radial mycelial growth inhibition. There was no significant difference among different concentrations of citronella oil $(1-5 \mu \mathrm{L})$ with respect to mycelial inhibition (Figure 07 and 08).
According to Ranasinghe et al., (2002) cinnamon oil and clove oil inhibited in-vitro mycelial growth of $C$. musae responsible for anthracnose of banana fruits. Similar to the present study Rodrigues et al., (2018) who studied the efficacy of four essential oils against anthracnose of banana, found that all the tested concentrations $(2,4,6$ and $8 \mu \mathrm{l})$ of clove oil to be the most efficient in inhibiting mycelial growth, germination and sporulation of the pathogen.

Antimicrobial evaluation of essential oils in vapor-phase was done by using Disc volatilization method. It is a simple method and therefore, it could be used as a primary screening method for antifungal oils (Juan, 2015).

\section{$5 \mu \mathrm{l} /$ plate $\quad 4 \mu \mathrm{l} /$ plate $3 \mu \mathrm{l} /$ plate $2 \mu \mathrm{l} /$ plate $\quad 1 \mu \mathrm{l} /$ plate}

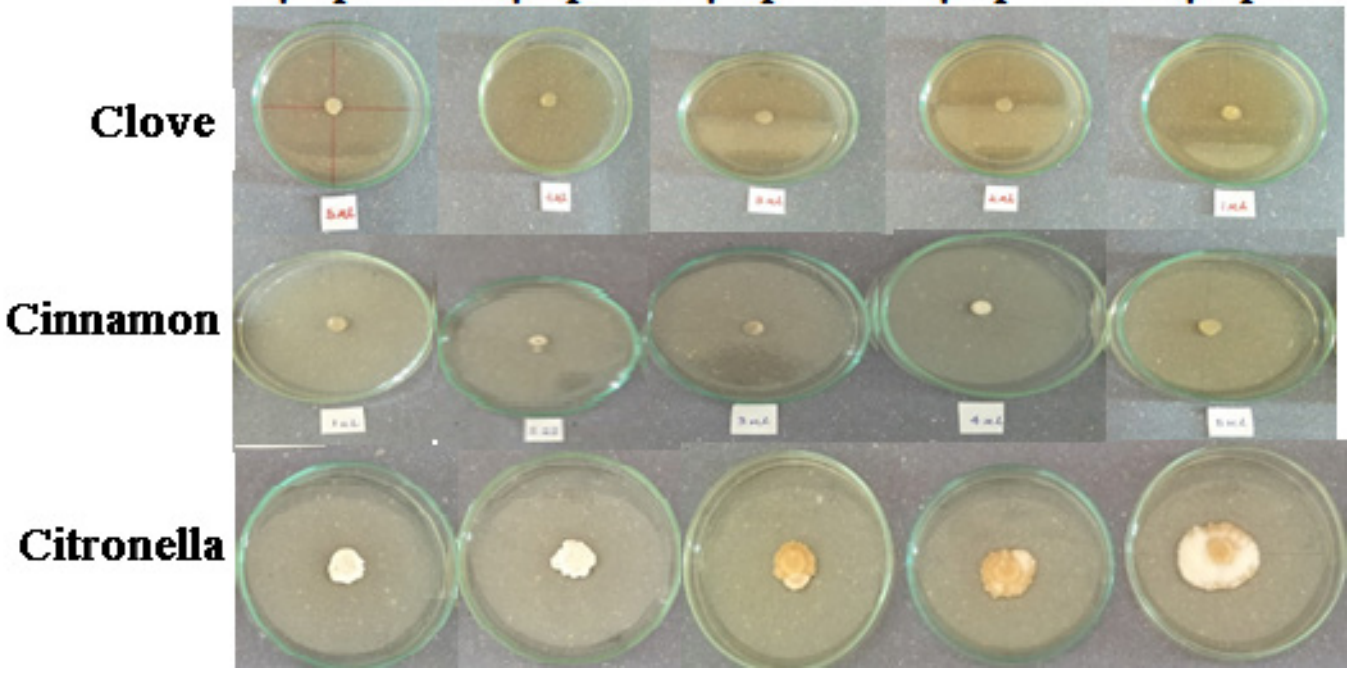

Figure 08: Mycelial growth of $\mathrm{C}$. siamense exposed to different concentrations of essential oils clove, cinnamon and citronella) at day seven. 
Essential oils and GRAS compounds to control anthracnose lesion development in mango fruit

The efficiency of minimum effective concentrations of GRAS compounds and Essential oils against lesion development by pathogen is shown in Table 02 .

Treatments of effective concentration levels which gave $100 \%$ inhibition of radial mycelial growth in-vitro condition were applied to the fruits. Those treatments which controlled the pathogenic fungus under in-vitro conditions effectively controlled the disease in-vivo conditions (Table 02), except sodium metabisulphite. Control treatment which was dipped in the sterilized distilled water gave the highest lesion diameter. According to the results, mean diameter of anthracnose lesion in all treatments were significantly $(\mathrm{p}<0.0001)$ smaller than that of the control treatment seven days after inoculation of the pathogen.

Hundred percent (100\%) lesion development of $C$. siamense was inhibited by sodium bicarbonate, clove oil and cinnamon oil similar to chlorothalonil fungicide in-vivo conditions. There was no statistically significant difference among these four treatments. According to the results sodium metabisulphite gave the second best results in controlling anthracnose in mango.

Though, some treatments were effective against the fungus under in-vitro conditions, the effectiveness of the same treatments could be different under in-vivo conditions.

Results of the this study was similar to the findings of Ranasinghe et al., (2002) who reported clove and cinnamon essential oils could be utilized as alternatives to postharvest treatments against anthracnose disease in banana. According to Maqbool et al., (2010) cinnamon oil with fungitoxic or fungistatic activity could be considered as the best alternative to synthetic fungicides for managing anthracnose in bananas. Essential oils have an aromatic nucleus and $\mathrm{OH}$ group which is responsible for the antimicrobial activity of essential oils by initiating hydrogen bonds with enzymes in microorganisms (Farrag et al.,1989).
Cinnamaldehyde and eugenol are the main chemical components of cinnamon oil and clove oil (Paranagama et al., 2001; Alma et al., 2007). Phenolic compounds of cinnamaldehyde and eugenol are responsible for the antibacterial and antifungal properties of essential oils. According to Shelef(1983) phenolic compounds mainly target the cell wall of pathogens and these phenolic compounds may damage the permeability barrier of cell membrane and inhibit respiration. Some studies have revealed that the essential oils may affect the metabolic pathways of microorganisms.

Treatment with plant essential oils has been evident as useful eco-friendly alternative to control postharvest losses of fruits, which are caused by some fungal species during storage (Sivakumar and Bautista-Baños, 2014). According to the results of Hasan et al., (2012) sodium bicarbonate treated papaya fruits effectively controlled the anthracnose disease development and delayed ripening of fruits.

According to Fischer et al., (2009) one-minute dipping of avocado fruits in sodium bicarbonate reduced disease development by $35 \%$ suggesting that a longer dipping time may lead to increased efficiency. But present results are contradictory to this theory. Both 15 minute and 30 minute dipping with sodium bicarbonate did not show any significant difference in disease development in Tom EJC mango fruits.

Present study revealed the efficacy of the safe compounds in comparison to recommended fungicide in controlling $C$. siamense under in -vivo conditions. However, some studies have reported the presence of the residues of the fungicides in the edible portions of the fruits. Abeyesekera et al.,(1997) described that fruits may become unsuitable for human consumption with the presence of residues in the edible portions of the fruits. Chlorothalonil is the recommended fungicide to control anthracnose disease. Chlorothalonil can have adverse effects on human health leading to human carcinogen, effects on kidney, urethra, bladder, etc., (Sweet, 1997). 
Table 02: Mean lesion diameter developed on Tom EJC mango fruits seven days after inoculation of Colletotrichum siamense.

\begin{tabular}{lc}
\hline \multicolumn{1}{c}{ Treatment } & $\begin{array}{c}\text { Mean lesion diameter appear } \\
\text { on fruit }(\mathrm{cm})\end{array}$ \\
\hline Clove oil (T1) & 0.000 \\
Cinnamon oil (T2) & 0.000 \\
Sodium bicarbonate 30 minutes dipping (T3) & 0.000 \\
Sodium bicarbonate 15 minutes dipping (T4) & 0.000 \\
Sodium metabisulphite 30 minutes dipping (T5) & $0.950 \mathrm{~b} \pm 0.05$ \\
Sodium metabisulphite 15 minutes dipping (T6) & $0.975 \mathrm{~b} \pm 0.025$ \\
Chlorothalonil (T7) & 0.000 \\
Control (T8) & $1.450 \mathrm{a} \pm 0.05$ \\
CV & 8.888 \\
\hline
\end{tabular}

Means with the same letter along the same column are not significantly different at $P=0.05$

\section{Physiochemical properties of treated fruits}

Physiochemical properties ( $\mathrm{pH}$, Total soluble solids and Titrable acidity) of treated and nontreated mango fruits were assessed (Table 03).

Highest $\mathrm{pH}$ value, $5.735 \pm 0.375$ was recorded in control treatment. The lowest value, $4.745 \pm 0.185$ was in the sodium metabisulphite 15 minutes dipping treatment. $5.35 \mathrm{pH}$ value was recorded in the fungicide treated fruits (T7). There was no statistically significant difference between the treated and non-treated fruits.

The highest total soluble solid content was recorded in the sodium bicarbonate 30 minutes dipping treatment. The lowest value was recorded in the sodium metabisulphite 15

\section{Table 03: $\quad$ pH values}

minutes dipping treatment. However, there was no significant difference between the treated and non-treated fruits.

The highest acidity value of 0.1125 was recorded in the sodium metabisulphite 30 minutes dipped fruits. Sodium bicarbonate 30 minutes dipped fruits recorded the lowest acidity value of 0.0895. There was no significant difference between the treated and non- treated fruits.

Present Physicochemical results are similar as Ranasinghe et al., (2003) who reported the effectiveness of essential oils on quality parameters of banana fruits and found that cinnamon and clove oils had no effect on total soluble solid (TSS) content, $\mathrm{pH}$ and total organic acidity of oil-treated fruits.

\begin{tabular}{cccc}
\hline Treatments & $\mathrm{pH}$ value & Brix value & Acidity \\
\hline control & $5.735 \pm(0.375)$ & $15.75 \pm(1.25)$ & $0.1065 \pm(0.0125)$ \\
T1 & $5.255 \pm(0.065)$ & $19.7 \pm(1.6)$ & $0.0895 \pm(0.0045)$ \\
T2 & $4.795 \pm(0.295)$ & $14.73 \pm(0.73)$ & $0.105 \pm(0.005)$ \\
T3 & $4.92 \pm(0.35)$ & $12.95 \pm(2.45)$ & $0.1125 \pm(0.0025)$ \\
T4 & $4.745 \pm(0.185)$ & $11.5 \pm(1.3)$ & $0.095 \pm(0.011)$ \\
T5 & $4.94 \pm(0.42)$ & $13.35 \pm(0.75)$ & $0.09 \pm(0.005)$ \\
T6 & $5.22 \pm(0.46)$ & $16 \pm(1.9)$ & $0.106 \pm(0.012)$ \\
T7 & $5.35 \pm(0.15)$ & $14.6 \pm(0.6)$ & $0.1095 \pm(0.0135)$ \\
\hline
\end{tabular}

Total soluble solids (Brix values) and Acidity of fruits after treatments of Sodium bicarbonate 30 minutes dipping (T1), Sodium bicarbonate 15 minutes dipping (T2), Sodium metabisulphite 30 minutes dipping (T3), Sodium metabisulphite 15 minutes dipping (T4), Clove (T5), Cinnamon (T6), Fungicide (T7).

Vertical bars represent average values with \pm standard error $(n=2)$ 


\section{CONCLUSION}

Colletotrichum siamense was identified as the causative agent of anthracnose disease in Tom EJC mango fruits.Clove oil, cinnamon oil and Sodium bicarbonate of $80000 \mathrm{ppm}$ concentration have effectively inhibited the radial mycelial growth of Colletotrichum siamense in both invitro and in-vivo conditions. Both 15 minutes and 30 minutes dipping time with GRAS compounds have yielded similar results. There were changes of physiochemical properties of fruits due to application of all GRAS compounds (except sodium metabisulphite) and volatile oils, in comparison to the control and fungicide treatment.

There is a novel approach to integrate chemicals with GRAS compounds, essential oils and biotic agents along with host plant resistance for managing plant diseases. It needs fewer amounts of chemicals, with minimum interference of biological equilibrium (Papavizas, 1973) when compared to chemical usage in controlling plant diseases (Nagesh, 2000; Cox Caroline, 1997).

GRAS compounds and essential oils have solutions for some problems associated with the use of synthetic fungicides because GRAS compoundsandessentialoilsareenvironmentally safe, renewable, available, easily accessible, largely non phytotoxic, relatively cost effective and hence can be considered as a constitute suitable plant protection in the strategy of disease management. Findings of the present study can be used in designing effective integrated management practices to control postharvest diseases of economically important fruits.

\section{REFERENCES}

Abdolahi A., Hassani A., Ghosta Y., Bernousi I. and Meshkatalsadat M.H. (2010). Study on the potential use of essential oils for decay control and quality preservation of tabarzeh table grape. Journal of Plant Protecttion Research. 50:45-52.

Abeysekara M., Nettikumar N.A.L.A., Wijeratnam R.S.W. and Sivakumar D. (1997). Studies on pre harvest treatments for control of postharvest pathogens. Australian Horticultural proceedings. 154-152.

Alma M.H., Ertas M., Nitz S. and Kollmannsberger H. (2007). Chemical composition and content of Essential oil from the bud of cultivated Turkish clove (Syzygium aromaticum L). BioResources. 2(2):265-269.

Ali Shtayeh M.S. and Abu Ghdeib S.L. (1999). Antimycotic activity of twenty-two plants used in folkloric medicine in the Palestinian area for treatment of skin diseases suggestive of dermatophyte infection. Mycoses. 42:665-672.

Anthony S., Abeywickrama K., Dayananda R., Wijeratnam S.W. and Arambewela L.(2004). Fungal pathogens associated with banana fruit in Sri Lanka and their treatment with essential oils. Mycopathologia. 157: 91-97.

Arauz L. (2000). Mango anthracnose: economic impact and current options for integrated management. Plant Diseases. 84: 600-611.

Bill M., Sivakumar D., Van Rooyan Z. and Mavuso Z.S.(2015). Newmethods of post-harvest disease control using thyme oil fumigation. South African avocado growers' association year book. 38: 98-104.

Cox Caroline. (1997). Fungicide Factsheet: Chlorothalonil. Journal of Pesticide Reform. 17(4): 14-20. 
Dafarera D.J., Ziogas B.N., Polissiou M.G. (2000). Analysis of essential oils from some greek aromatic plants and their fungitoxicity on Penicillium digitatum. Journal of Agricultural of Food Chemistry. 48:2576-2581.

Dissanayake P.K., Dissanayake M. L. M. C. and Wijesekara W. M. A. U. M. (2015). Effect of Hot Water Treatments on Postharvest Life of Seeni Kesel Banana (Musa spp.cv. Seeni KeselPisang Awak, ABB).Journal of Agriculture and Ecology Research International2(4): 209218. DOI: $10.9734 / J A E R I / 2015 / 14011$

Dissanayake M.L.M.C., Kashima R., Tanaka S.,Ito S. (2009). Pathogenic variation and molecular characterization of Fusarium species isolated from wilted Welsh onion in Japan. Journal of Genetics and Plant Pathology. 75:37-45. https://doi.org/10.1007/s10327-008-0135-z

Duamkhanmanee R. (2008). Natural essential oils from lemon grass (Cymbopogon citratus) to control postharvest anthracnose of mango fruit. International Journal of Biotechnology, London. 1:104-108.

Farrag R.S., DawZ.,YandS.H., Abo-Raya. (1989). Influence of some spice essential oils onAspergillus parasiticus growth and production of aflatoxins in a synthetic medium. Journal of Food Science. 54:74-76.

Fisher K., Phillips C. and Mc Watt L. (2009). The use of an antimicrobial citrus vapour to reduce Enterococcus sp. on salad products. International Journal of Food Science and Technology. 44(9):1748- 1754.

Fitzell R.D. and Peak C.M. (1984). The epidemiology of anthracnose disease of mango.Annals of Applied Biology. 104:53-59.

Hasan M.F., Mahmud T.M.M., Kadir J., Ding, P., Zaidul I.S.M. (2012). Sensitivity of Colletotrichum gloeosporioides to sodium bicarbonate on the development ofanthracnose in papaya (Carica papaya L. cv. Frangi). Australian Journal of Crop Science. 6:17-22.

Juan B. (2015). Models of evaluation of antimicrobial activity of essential oils in vapour phase: a promising use in healthcare decontamination. Bio prospecting development and consulting, Bogota, Colmobia. Volatiles \& essential oils. 2(2):16-29.

Lewthwait S.E., Detnetener P.R. and Greenwood D.R. (1997). Sodium bicarbonate GRAS compound and associated emulsifiers for insect control. Australian Horticultural proceedings. 142-147.

Mahendranathan, C. (2018). Evaluation of Postharvest losses of mango (Mangifera indica) in Batticaloa district, Sri Lanka and reducing stem end rot disease by retention of latex at harvest. Plant science \& Natural Medicine,Paris, France. DOI: 10.4066/2591-7897-C1-003

Maqbool M., Ali A. and Alderson P.G. (2010). Effect of cinnamon oil on incidence of anthracnose disease and postharvest quality of bananas during storage. International Journal of Agriculture and Biology.12:516-520.

Meepagala K. M., Sturtz G. and Wedge D. E. (2002). Antifungal constituents of the essential oil fraction of Artemisia drancunculus L. var. dracunculus. Journal of Agricultural Food and Chemistry. 50:6989-6992. 
Mills A.A.S., Platt H.W., Hurta R.A.R. (2004). Effect of salt compounds on mycelial growth, sporulation andspore germination of various potato pathogens. Postharvest Biology and Technology. 34:341-350.

Nagesh G.K. (2000). Investigation on sunflower rust caused by Puccinia helianthi Schw.M.Sc. (Agri.) Thesis, Uni. Agric. Sci., Dharwad, India.

Narayanasamy P. (2006). Disease development and symptom expression. In: Post-harvest Pathogens and Disease Management. Wiley- Interscience, John Wiley \& Sons. 117-189. https://doi.org/10.1002/0471751987.ch4

Olıvier C., Halseth D.E., Mizubut E.S.G., Lorıa R. (1998). Postharvest application of organic and inorganic salts for suppression of silver scurf on potato tubers. Plant Disease. 82:213-217.

Papavizas G.C. (1973). Status of biological control of soil borne pathogen. Soil Biology And Biochemistry 5:709.

Paranagama P.A., Wimalasena S., Jayatilake G.S., Jayawardena A.L., Senanayake U.M., Mubarak A.M. (2001).A comparison of essential oil constituents of bark, leaf, root and fruit of cinnamon (Cinnamomum zeylanicum Blum) grown in Sri Lanka. Journal of National Science Foundation of Sri Lanka. 29(3):147-153.

Ranasinghe L. S., Jayawardena B. and AbeywickramaK. (2003). Use of waste generated from cinnamon bark oil extraction as a postharvest treatment of 'Embul' banana. Food, Agriculture and Environment.1:340-344.

Ranasinghe L., Jayawardena B. and Abeywickrama K. (2002). Fungicidal activity of essential oils of Cinnamomum zeylanicum (L.) and Syzygium aromaticum (L) Merr et L.M. Perry against crown rot and anthracnose pathogens isolated from banana. Lett. Applied Microbiology. $35: 208-211$.

Rodrigues M.L.M., Mizobutsi E.H., Nacarath I.R.F.F., Fernandes M.B., Mizobutsi G.P.,Ribeiro R.C.F.,Reis S. T.D., Pinheiro J.M.S., Prates P.J.L.,\& Lage G.G.A. (2018). Essential Oils in the Control of Anthracnose on 'Prata Ana'Banana. Journal of Agricultural Science. 10(9):116-124.

SalunkheD. K. B. and Desai B. (1984). Postharvest biotechnology of fruits. Volume 2. CRC Press. the University of Wisconsin - Madison. USA.168pp

Shelef L. A. (1983). Antimicrobial effects of spices. Journal of Food Safety. 6:29-44.

Sivakumar D. and Bautista-Baños S. (2014). A review on the use of essential oils for postharvest decay control and mainte- nance of fruit quality during storage. Crop Protect. 64:27-37.

Sivakumar D., Wilson Wijeratnam R.S. and AbesekereM.(1999). Invetigations on the control of postharvest pathogens of Rambutan, Malwana special selection 1, via the use of GRAS compounds. $12^{\text {th }}$ Biennial Conference of the Australian Plant pathologySociety on "Asia Pacific Plant pathology for the new Millenium”. Australia September. 27-29.

Sivakumar D., Hewarathgamage N.K., Wilson Wijeratnam R.S., and Wijesundera R.L.C.(2002). Effect of ammonium carbonate and sodium bicarbonate onanthracnose of papaya Phytoparasitica. 30 (5):486-492.

Smith L.G. (1980). Cost of controlling "blackspot” repaid in better prawn prices. AustralianFisheries January: 49-53. 
Stattery S. Williams D. and Deeth H. (1990). Meta dipping most effective for blackspot. Australian Fisheries April: 25-27.

Sweet D.V. (1987). Registry of Toxic Effects of Chemical Substances Microfiche. NIOSH, Washington, DC.

Tafinta I.Y., Shehu K., Abdulganiyyu H., Rabe A.M., Usman A. (2013). Isolation and identification of fungi associated with the spoilage of sweet orange (Citrus sinensis) fruits in Sokoto State. Nigerian Journal of Basic and Applied Science. 21(3):193-196.

Tripathi P. andDubey N. (2004). Exploitation of natural products as an alternative strategy to control postharvest fungal rotting of fruit and vegetables. Postharvest Biology and Technology. $32(3): 235-245$.

Wijesinghe M.A.R.N., Sarananda K.H. and Mendis B.E.P. (2011). The Effect of pre -harvest application of potassium on fruit quality of "TJC" mango (Mangifera indica L.) selected for processing. Proceedings of University of Peradeniya Research Sessions, Sri Lanka. 